

\title{
Sillares
}

Revista de Estudios Históricos

http://sillares.uanl.mx/

\section{Las causas de canonización en la Arquidiócesis de Monterrey}

\section{The causes of canonization in the Archdiocese of Monterrey}

\author{
Moisés Alberto Saldaña Martínez \\ Universidad Autónoma de Nuevo León \\ orcid.org/0000-0003-0627-6203
}

Recibido: 15 de septiembre de 2021

Aceptado: 13 de octubre de 2021

Publicado: 1 de enero de 2022

Copyright: (C) 2022, Moisés Alberto Saldaña Martínez. This is an open-access article distributed under the terms of Creative Com-mons Attribution License [CC BY 4.0], which permits unrestrict-ed use, distribution, and reproduction in any medium, provided the original author and source are credited.

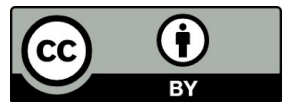

DOI: https://doi.org/10.29105/sillares1.2-5 


\section{Las causas de canonización en la Arquidiócesis de Monterrey}

The causes of canonization in the Archdiocese of Monterrey

Moisés Alberto Saldaña Martínez

Universidad Autónoma de Nuevo León

orcid.org/0000-0003-0627-6203

Resumen: El artículo busca analizar el significado de los procesos de canonización que han sido encausados por la Iglesia regiomontana. Se explica primeramente el significado de la santidad en el catolicismo, así como el proceso de canonización que se sigue institucionalmente. Se analizan enseguida las causas mexicanas, desde la época virreinal. Posteriormente, se abordan las devociones neoleonesas y los procesos de la arquidiócesis regiomontana, es decir: el arzobispo Guillermo Tritschler, los sacerdotes Juan José Hinojosa, Raymundo Jardón y Pablo Cervantes, y la religiosa sor Gloria Elizondo. Finalmente, se presenta una interpretación sobre las causas de canonización de Monterrey, considerando su temporalidad, perfil de los candidatos y su número, entre otros factores. Se ha recurrido a múltiples fuentes bibliográficas especializadas para el abordaje de la temática.

Palabras clave: Iglesia católica; canonizaciones; santos mexicanos; Nuevo León; Historia de la religión.

Abstract: The article seeks to analyze the meaning of the canonization processes that have been prosecuted by the Monterrey Church. First of all, it is explained the meaning of holiness in Catholicism, as well as the canonization process that is followed institutionally. Afterwards, Sillares, vol. 1, núm. 2, 2022 
the Mexican causes are analyzed, since the colonial era. Subsequently, the devotions of Nuevo León and the processes of the Monterrey archdiocese are addressed, that is: Archbishop Guillermo Tritschler, priests Juan José Hinojosa, Raymundo Jardón and Pablo Cervantes, and the religious sister Gloria Elizondo. Finally, an interpretation of the canonization processes of Monterrey is presented, considering their temporality, the number of candidates, their profiles, among other factors. Multiple specialized bibliographic sources have been used to address the issue.

Keywords: Catholic Church; canonizations; Mexican saints; Nuevo León; History of religion. 


\section{Introducción}

El catolicismo comenzó a tener presencia en el territorio del Nuevo Reino de León desde 1582, cuando algunos religiosos, como fray Juan de la Magdalena, acompañaron a Luis Carvajal y de la Cueva. ${ }^{1}$ Es decir, hace casi 440 años que se sentaron las bases del Evangelio en dicha región, lo cual ha implicado una historia extensa y compleja, plena de personajes significativos, religiosos y laicos. Sin embargo, sólo cinco personas se hallan en proceso de canonización, quienes realizaron su labor en poco más de 50 años (de 1913 a 1966) y cuyas causas fueron introducidas en sólo cuatro años (entre 1991 y 1995).

A partir de lo anterior, se puede formular el siguiente problema: ¿qué significado manifiestan los cinco procesos de canonización postulados por la Arquidiócesis de Monterrey, en el contexto de la sociedad regiomontana contemporánea? En el presente texto se buscará dar respuesta a este cuestionamiento, para postular una interpretación que establezca las particularidades de los procesos de canonización neoleoneses.

\section{El largo camino hacia el altar}

Si bien la Iglesia católica afirma que "[t]odos son llamados a la santidad", sostiene también que "las gracias especiales o los signos extraordinarios de esta vida mística [son] concedidos solamente a algunos para manifestar así el don gratuito hecho a to-

1 Israel Cavazos Garza, Breve historia de Nuevo León (México, DF: El Colegio de México, 1994), 31.

Sillares, vol. 1, núm. 2, 2022

DOI: https://doi.org/10.29105/sillares1.2-5 
dos". ${ }^{2}$ Estas personas son los santos (del latín sanctus, a su vez del griego " "ó $\gamma 10 \varsigma$ ", sagrado, que alude a alguien o algo "apartado"), de quienes se cree que están en el cielo "glorificados, contemplando "claramente a Dios"'. A ellos se les profesa "especial veneración" (llamada "dulía" desde el Segundo Concilio de Nicea de 787), se busca el "auxilio de su intercesión" y se postula que sus "carismas divinos los [hacen] recomendables a la piadosa devoción e imitación de los fieles". ${ }^{3}$ Los carismas son definidos como "gracias del Espíritu Santo, que tienen directa o indirectamente una utilidad eclesial $[\ldots y]$ están ordenados $[\ldots]$ al bien de los hombres y a las necesidades del mundo". ${ }^{4}$

Por otro lado, en los primeros siglos del cristianismo el culto a los santos se dio de manera espontánea o bien sancionado por las Iglesias particulares. Sin embargo, desde el siglo X Roma comenzó a abrogarse el derecho a proclamar a los santos, hasta que en 1170 el papa Alejandro III reservó dicha prerrogativa definitivamente a la Santa Sede. ${ }^{5}$ En 1588 Sixto V creó la Sagrada Congregación de Ritos, que gestionó los procesos de

2 “Catecismo de la Iglesia Católica", sec. 2013 y 2014, consultado el 11 de julio de 2018, http://www.vatican.va/archive/catechism_sp/p3s1c3a2 sp.html\#IV La santidad cristiana.

3 "Lumen Gentium. Constitución Dogmática sobre la Iglesia", sec. 50, consultado el 11 de julio de 2018, http://www.vatican.va/archive/hist_councils/ ii_vatican_council/documents/vat-ii_const 19641121_lumen-gentium_sp.html. 4 "Catecismo de la Iglesia Católica", sec. 799.

5 Williams Smith y Samuel Cheetham, A Dictionary of Christian Antiquities (https://archive.org/stream/dictionaryofchri01smituoft/dictionaryofchri01smituoft_djvu.txt, 1875), 283.

Sillares, vol. 1, núm. 2, 2022

DOI: https://doi.org/10.29105/sillares1.2-5 
canonización; Urbano VIII emitió nuevas normas en 1634 y 1642, así como Próspero Lambertini entre 1734 y 1738, y dichas disposiciones se incorporaron al Código de Derecho Canónico de 1917. ${ }^{6}$ De tal modo, los procedimientos para la canonización de una persona han variado a lo largo de los siglos y actualmente rige una normativa establecida por el papa Juan Pablo II en 1983, bajo la Constitución Apostólica Divinus Perfectionis Magister. Y, derivado de dicha legislación general, se promulgó el mismo año el documento Normae servandae in inquisitionibus ab Episcopis faciendis in Causis Sanctorum.

Cabe precisar que "[1]a causa de beatificación y canonización se refiere a un fiel católico que en vida, en su muerte y después de su muerte tuvo fama de santidad, viviendo heroicamente todas las virtudes cristianas; o bien goza de fama de martirio". La "fama de santidad es la opinión extendida entre los fieles acerca de la pureza e integridad de vida del [candidato a santo] y acerca de que éste practicó las virtudes en grado heroico". ${ }^{7}$ De tal modo, hasta 2017 existían ordinariamente dos itinera (vías) para iniciar el

6 Juan Pablo II, "Divinus Perfectionis Magister. Constitución Apostólica so-
bre la nueva legislación relativa a las Causas de los Santos", consultado el 11
de julio de 2018, http://w2.vatican.va/content/john-paul-ii/es/apost_constitu-
tions/documents/hfjp-ii_apc_25011983_divinus-perfectionis-magister.html.
7 "Sanctorum Mater. Instrucción sobre el procedimiento instructorio dioce-
sano o eparquial en las Causas de los Santos", secs. 4-6, consultado el 11 de
julio de 2018, http://www.vatican.va/roman_curia/congregations/csaints/do-
cuments/rc_con_csaints_doc_20070517_sanctorum-mater_sp.html\#INTRO-
DUCCIÓN.

Sillares, vol. 1, núm. 2, 2022

DOI: https://doi.org/10.29105/sillares1.2-5 
proceso de canonización: las virtudes heroicas y el martirio. ${ }^{8}$ Sin embargo, dentro del proceso también es importante la "fama signorum", que es "la opinión difundida entre los fieles acerca de las gracias y favores recibidos a través de la intercesión del siervo de Dios", ${ }^{9}$ es decir, los milagros que se le atribuyen. Enseguida se describirán los pasos del camino hacia la santidad.

En primera instancia, se halla la fase preliminar del proceso. Existen tres figuras destacadas en esta etapa: el obispo diocesano en cuya jurisdicción haya fallecido el candidato a santo y a quien compete el derecho de investigación; ${ }^{10}$ el actorpromotor (cualquier persona física o jurídica perteneciente a la Iglesia), quien promueve la causa de canonización y asume la responsabilidad moral y económica del proceso; y el postulador (un sacerdote, religioso o laico), designado por el actor con la aprobación del obispo, quien investiga sobre la vida y méritos del candidato, da seguimiento al desarrollo del proceso instructorio y administra los recursos económicos. ${ }^{11}$

8 El 11 de julio de 2017, el papa Francisco agregó un tercer iter: el ofrecimiento de la vida. Véase: Francisco, "Maiorem hac Dilectionem. Carta Apostólica en forma de «Motu Proprio» sobre el ofrecimiento de la vida", consultado el 12 de julio de 2018, https://w2.vatican.va/content/francesco/ es/motu_proprio/documents/papa-francesco-motu-proprio_20170711_maiorem-hac-dilectionem.html

9 "Sanctorum Mater. Instrucción sobre el procedimiento instructorio diocesano o eparquial en las Causas de los Santos", sec. 6.

10 Juan Pablo II, "Divinus Perfectionis Magister. Constitución Apostólica sobre la nueva legislación relativa a las Causas de los Santos", sec. 1.

11 "Normae servandae in inquisitionibus ab Episcopis faciendis in Causis Sanctorum. Constitución sobre las normas que han de observarse en las inSillares, vol. 1, núm. 2, 2022

DOI: https://doi.org/10.29105/sillares1.2-5 
Las causas pueden ser recientes (cuando existen aún testigos vivos) o antiguas (cuando tienen que sustentarse en documentos y testimonios históricos no orales). Para las causas recientes, deben haber transcurrido cinco años desde el fallecimiento del candidato, pero preferentemente no más de treinta, pues de otro modo debe justificarse el retraso para incoar la causa. ${ }^{12}$ Una vez reunida la documentación necesaria (como la biografía del potencial santo y los escritos que éste haya emitido), se presenta al obispo la petición de instrucción de la causa y el candidato pasa a denominarse siervo de Dios. ${ }^{13} \mathrm{El}$ obispo debe consultar con los demás obispos de la región, con los fieles y con la Santa Sede si existe algún inconveniente para iniciar el proceso. El Vaticano analiza la ortodoxia de los escritos e ideas del potencial santo y, si no existe objeción, se emite un Nihil Obstat para la introducción de la causa. ${ }^{14}$

Habiéndose superado estas consultas, se inicia formalmente el proceso a nivel diocesano y el obispo nombra a los miembros del Tribunal que realizará la investigación, el cual

vestigaciones que hagan los obispos en las Causas de los Santos", secs. 1-3, consultado el 12 de julio de 2018, http://www.causesanti.va/content/causadeisanti/it/documenti/normae-servandae es.html.

12 "Normae servandae in inquisitionibus ab Episcopis faciendis in Causis Sanctorum. Constitución sobre las normas que han de observarse en las investigaciones que hagan los obispos en las Causas de los Santos", sec. 7 y 9.

13 "Sanctorum Mater. Instrucción sobre el procedimiento instructorio diocesano o eparquial en las Causas de los Santos", sec. 4.

14 "Sanctorum Mater. Instrucción sobre el procedimiento instructorio diocesano o eparquial en las Causas de los Santos", secs. 41-46.

Sillares, vol. 1, núm. 2, 2022

DOI: https://doi.org/10.29105/sillares1.2-5 
es presidido por el propio obispo (o su delegado) e incluye a un promotor de justicia, los notarios, los censores teólogos, y los peritos en historia y archivística. A ellos compete escudriñar y analizar la documentación, e interrogar a los testigos (si los hay) en torno a la causa. ${ }^{15}$ Para concluir la etapa diocesana, el obispo o su delegado deben visitar el sepulcro, la casa donde vivió, el lugar donde murió y demás espacios relacionados con el siervo de Dios para verificar que no se le rinde culto público prohibido (sólo es lícito el culto privado). ${ }^{16}$

Tras la integración de los documentos, actas y testimonios de la causa, todo el material se envía a la Congregación para las Causas de los Santos en El Vaticano, con lo que da inicio la fase romana del proceso. Dicha Congregación, primeramente, decreta la validez jurídica de la causa y designa un relator, el cual asesora y revisa la elaboración del documento sobre la vida y obra del siervo de Dios. Dicho texto se denomina Positio super vita, virtutibus et fama sanctitatis, y consta de dos partes: el sumario (selección de los mejores textos del proceso diocesano) y la información sobre la vida, las virtudes y la fama de santidad del candidato (su historia de vida y los testimonios sobre sus virtudes y fama probada de santidad).

15 "Normae servandae in inquisitionibus ab Episcopis faciendis in Causis Sanctorum. Constitución sobre las normas que han de observarse en las investigaciones que hagan los obispos en las Causas de los Santos", secs. 14-27.

16 "Normae servandae in inquisitionibus ab Episcopis faciendis in Causis Sanctorum. Constitución sobre las normas que han de observarse en las investigaciones que hagan los obispos en las Causas de los Santos", sec. 28.

Sillares, vol. 1, núm. 2, 2022 
Enseguida, la Positio debe ser revisada por ocho censores teólogos y, si éstos dan su aprobación, pasa al análisis de la Congregación ordinaria de cardenales y obispos. Si el informe de estos clérigos es positivo, el papa emite el Decreto de las virtudes heroicas o el Decreto sobre el martirio, y desde ese momento el candidato recibe el título de venerable. Tras este paso, los mártires pueden ser declarados beatos, es decir, se autoriza su culto público a nivel diocesano y su conmemoración se incluye en el Martirologio.

Pero en el caso de aquellos que sólo se han reconocido sus virtudes heroicas, debe haber un milagro "probado científicamente" (por lo regular, se trata de una sanación "inexplicable médicamente" que se atribuye a su intercesión), para que pueda ser beatificado. En estos casos, será necesario probar un segundo milagro (ordinariamente, a los mártires no se les exigen milagros como requisito) para que culmine el proceso con la canonización, es decir, que el papa proclame solemnemente al beato como santo y autorice su culto público en la Iglesia universal. ${ }^{17}$ Los milagros son interpretados como una confirmación divina de la santidad del candidato, es decir, como una especie de juicio de Dios.

17 Juan Pablo II, "Divinus Perfectionis Magister. Constitución Apostólica sobre la nueva legislación relativa a las Causas de los Santos", secs. 13-16; "Causas de Canonización. Pasos hacia la canonización", Familia de la Cruz, consultado el 12 de julio de 2018, http://www.causascanonizacion.org/pasoshacialacanonizacion.htm.

Sillares, vol. 1, núm. 2, 2022

DOI: https://doi.org/10.29105/sillares1.2-5 
Todo el proceso puede durar muchos años, incluso siglos. Han existido procedimientos sumamente rápidos (san Antonio de Padua, canonizado en 1232, menos de un año después de morir) y procesos muy parsimoniosos (santa Hildegarda de Bingen, fallecida en 1179 y canonizada en 2012). Asimismo, hay casos que se estancaron sin motivos de peso, como los procesos del cardenal Cisneros y la reina Isabel I de Castilla. Los motivos políticos y económicos suelen estar detrás de estos obstáculos.

\section{Santos y beatos mexicanos}

Durante la época hispánica de América los criollos ansiaron la canonización de santos autóctonos, bajo la premisa de que si su tierra era fértil en frutos de santidad, ello los equiparaba a los europeos. Así, desde el siglo XVII se buscó la canonización de personas, cuyo origen o lugar de acción hubiese sido América. Pero sólo se verificó la canonización de una mujer americana durante toda la etapa colonial: la criolla limeña Isabel Flores de Oliva, llamada Rosa de Santa María (santa Rosa de Lima), cuyo proceso fue relativamente rápido, pues fue canonizada en 1671 apenas 54 años después de su muerte.

Puede agregarse otro santo proclamado durante la época virreinal, cuya labor se desarrolló en el Nuevo Mundo aunque era originario de España: Toribio de Mogrovejo, (arzobispo de Lima, 1579-1606), quien fue canonizado en 1726. Por otro lado, sólo un novohispano llegó a ser beatificado: el criollo capitalino Felipe de las Casas y Martín, llamado Felipe de Jesús, fraile franciscano Sillares, vol. 1, núm. 2, 2022 200 DOI: https://doi.org/10.29105/sillares1.2-5 
que fue martirizado en 1597 en Nagasaki, Japón, junto con otros 25 cristianos. Pablo Miki encabezó a este grupo en el proceso de beatificación y el papa Urbano VIII los proclamó beatos en $1627 .{ }^{18}$

El martirio y la pertenencia de los candidatos a las órdenes de los franciscanos y jesuitas favoreció el proceso, donde quedó implicado el novohispano Felipe. Tras su beatificación, ascendió su culto en México: en 1638 se erigió su capilla en la Catedral de México, desde el año siguiente se celebró su fiesta el 5 de febrero, y fue venerado como Patrón de la Ciudad de México y de la Nueva España, llamándosele "san", pese a que sólo se hallaba beatificado. El único otro caso de beatificación durante la época novohispana fue el de Sebastián de Aparicio, franciscano nativo de España, fallecido en Puebla en 1600 y declarado beato en 1789 .

Sin embargo, estos escasos resultados no significaron que los criollos no promovieran más causas de quienes nacieron o laboraron en América, como fueron los casos de los obispos Juan de Palafox y Mendoza, y Francisco de Aguiar y Seixas, de las místicas sor María de Jesús de Tomelín y Catarina de San Juan, de los eremitas taumaturgos Gregorio López y fray Bartolomé de Jesús María, y del mártir de Japón fray Bartolomé Gutiérrez. Casi todos ellos vivieron en México y Puebla entre fines del siglo XVI

\footnotetext{
18 Antonio Rubial García, "Los santos milagreros y malogrados de la Nueva España”, en Manifestaciones religiosas en el mundo colonial americano, ed. Clara García Ayluardo y Manuel Ramos Medina (México, DF: Instituto Nacional de Antropología e Historia; Condumex - Centro de Estudios de Historia de México; Universidad Iberoamericana, 1997), 57.

Sillares, vol. 1, núm. 2, 2022 
y principios del XVII, y sus causas fueron introducidas a fines del siglo XVII y durante el siglo XVIII. Es significativa la ausencia de frailes evangelizadores entre estos primeros candidatos a la santidad.

Los promotores de estos procesos fueron los obispos o las órdenes religiosas, y los novohispanos apoyaron estas causas otorgando recursos económicos. No obstante, ninguno de estos procesos fue exitoso en aquella época ${ }^{19}$ por diversos motivos, como méritos insuficientes, aspectos heréticos, poco dinero para la promoción, o la procedencia étnica o social del candidato. Además, desde mediados del siglo XVIII la Corona limitó los procesos de canonización de americanos, por el potencial autonomista que implicaban. ${ }^{20}$ En efecto, Felipe de Jesús fue un emblema del nacionalismo criollo a fines del siglo XVIII.

Sin embargo, una nueva coyuntura política favoreció a los procesos de beatificación y canonización en el México independiente, durante la época de la Reforma. Así, el papa Pío IX canonizó en 1862 a Pablo Miki y compañeros, entre los que se encontraba Felipe de Jesús, y beatificó en 1867 a Bartolomé Gutiérrez y Bartolomé Laurel, ambos también religiosos, mártires en Japón y beatificados en grupo. Estas proclamaciones

19 Juan de Palafox fue beatificado en 2011; los procesos de Francisco de Aguiar, María de Jesús de Tomelín, Gregorio López y Bartolomé de Jesús María se estancaron, y Catarina de San Juan fue declarada heterodoxa por el Santo Oficio en 1696.

20 Rubial García, "Los santos milagreros y malogrados de la Nueva España", 58 y 59 .

Sillares, vol. 1, núm. 2, 2022

DOI: https://doi.org/10.29105/sillares1.2-5 
son interpretadas por algunos como "consecuencia de la urgente necesidad que tenía el papado de fortalecer al bando conservador frente a los anticlericales liberales". ${ }^{21}$

Sin embargo, después de la década de 1860 ningún mexicano volvió a ser elevado a los altares durante más de un siglo, hasta la beatificación del sacerdote jesuita Miguel Agustín Pro, zacatecano ejecutado en la Ciudad de México en 1927 acusado de participar en un atentado contra Obregón, por lo que fue declarado mártir. Su proceso inició desde 1935 y en 1952 su causa pasó a la fase romana, pero su martirio no fue reconocido oficialmente sino hasta 1986 por el papa Juan Pablo II y su beatificación se verificó en $1988 .^{22}$

Dos años después, en su segunda visita a México, el mismo pontífice beatificó en la Basílica de Guadalupe de la capital del país a tres nuevos beatos: el vidente guadalupano Juan Diego Cuauhtlatoatzin, el sacerdote José María Yermo y Parres, y los tres niños Cristóbal, Antonio y Juan, mártires de Tlaxcala. Los años siguientes se multiplicaron las beatificaciones de mexicanos: en 1992, el sacerdote Cristóbal Magallanes y 24 compañeros mártires de la persecución religiosa, y sor María Natividad Venegas de la Torre; en 1995, el obispo Rafael Guízar y Valencia; y en 1997, el sacerdote Elías del Socorro Nieves, mártir

21 Rubial García, 140.

22 Enrique Mendoza Delgado, "Miguel Agustín Pro, mártir de la fe", Revista Verbo, 1988, http://www.fundacionspeiro.org/verbo/1988/V-269270-P-1169-1194.pdf. 
en la época de la Guerra Cristera, y la religiosa María Vicenta de Santa Dorotea Chávez Orozco.

En mayo del año 2000, el papa Juan Pablo II canonizó a 27 beatos mexicanos (Cristóbal Magallanes y 24 compañeros, José María Yermo y María Natividad Venegas), con lo que se engrosó en una sola ceremonia el número de santos mexicanos, que pasó de uno a 28. Después de ese año, México ha sumado 7 santos y numerosos beatos más, de modo que cuenta actualmente con 35 santos y alrededor de 26 beatos. ${ }^{23}$ La más reciente beatificación fue la de Concepción Cabrera de Armida, acontecida el 4 de mayo de 2019.

Sin embargo, las múltiples canonizaciones y beatificaciones de las últimas décadas no han estado exentas de polémicas. En primera instancia, las causas de los numerosos mártires de la persecución religiosa de las décadas de 1920 y 1930 fueron generalmente impulsadas por los sectores más conservadores $\mathrm{y}$ opuestos al régimen priísta, ${ }^{24} \mathrm{y}$ algunos interpretaron las

23 El número preciso puede ser variable, según el criterio que se adopte, pues existen santos o beatos no originarios de México, pero que realizaron su labor en lo que es o fue territorio mexicano (como el español san Junípero Serra, que fue misionero en California), y existen quienes eran originarios de México, pero fueron martirizados y postulados en el extranjero (como el jalisciense beato Reginaldo Hernández Ramírez, ejecutado en España). Ver "Santos y beatos mexicanos", consultado el 14 de julio de 2018, http://www.arquidiocesisdepuebla. $\mathrm{mx} /$ index.php/arquidiocesis/santos-y-beatos-mexicanos/beatos?start=20.

24 "Los Tecos son considerados la parte más reaccionaria de la ultraderecha [...] y fueron los principales impulsores de la canonización de los 25 mártires de la Cristiada, resaltando así su carácter antagónico a las instituciones del Estado". Ver Mónica Uribe, "La ultraderecha en México: el conservadurisSillares, vol. 1, núm. 2, 2022 204

DOI: https://doi.org/10.29105/sillares1.2-5 
canonizaciones del año 2000 como un espaldarazo vaticano a la alternancia política. ${ }^{25}$ Además, estas causas han sido criticadas por otro motivo: el "'favoritismo exacerbado', que benefició a los sacerdotes y relegó a los mártires laicos, quienes fueron mayoría durante la persecución religiosa en México". En efecto, de los 25 mártires canonizados en 2000 sólo tres eran laicos, mientras que “durante la Guerra Cristera murieron como mártires por lo menos 200 laicos", al tiempo que "en ese mismo período, cayeron en total 90 sacerdotes", ${ }^{26}$

Otros mártires cuya santificación despertó suspicacias fueron los niños mártires tlaxcaltecas, porque su historia implicó "[1]a manipulación de la conciencia de niños y adolescentes para ponerlos al servicio de causas sagradas" ${ }^{27} \mathrm{y}$ "por la forma insidiosa de oponer a los hijos contra los padres e incitar deliberadamente la destrucción de las familias". ${ }^{28}$ Asimismo, la beatificación de los mártires de Cajonos generó críticas, ya que "delataban a los practicantes de la religión indígena, causando muertes y daños

mo moderno", El Cotidiano 23, núm. 149 (2008): 47, http://www.redalyc.org/ pdf $/ 325 / 32514905$.pdf.

25 "Consideran estrategia política la santificación de mártires", Reforma, consultado el 15 de junio de 2000, https://reforma.vlex.com.mx/vid/consideran-estrategia-santificacion-martires-80987604.

26 Rodrigo Vera, "La Iglesia discrimina a mártires laicos: Jean Meyer", Proceso, el 15 de abril de 2000, https://www.proceso.com.mx/183033/la-iglesia-discrimina-a-martires-laicos-jean-meyer .

27 Guillermo Bonfil Batalla, "Los niños mártires de Tlaxcala", Cuadernos Nexos, mayo de 1990, https://www.nexos.com.mx/?p=5829.

28 Enrique Florescano, Historia de las historias de la nación mexicana (México, DF: Taurus, 2002), 160.

Sillares, vol. 1, núm. 2, 2022

205

DOI: https://doi.org/10.29105/sillares1.2-5 
mediante su información a los encendidos misioneros", por lo que sus acciones pueden significar que "los padres y su pueblo eran malvados y la cultura indígena era mala". ${ }^{29}$

De igual modo, la canonización de José Sánchez del Río, adolescente de 14 años ejecutado por su simpatía hacia los cristeros, ha despertado cuestionamientos porque se "parece más, en los tiempos actuales a un joven suicida islámico", pudiendo postularse la pregunta: "¿[é]se es el modelo que quiere mostrar la Iglesia a los jóvenes actuales?". ${ }^{30}$ Por otro lado, la exaltación a los altares de Juan Diego fue duramente criticada por las dudas sobre su historicidad, siendo incluso descalificada por el abad de la Basílica de Guadalupe, Guillermo Schulenburg. ${ }^{31}$ Otro caso polémico fue el del obispo Rafael Guízar y Valencia, no tanto por él mismo, sino porque era tío abuelo de Marcial Maciel y su causa fue ampliamente impulsada por los Legionarios de Cristo, e interpretada como una exaltación del fundador de la orden; ${ }^{32}$ cabe agregar que la madre de Maciel, Maura Degollado, también se encuentra en proceso de canonización.

Asimismo, hay otros cuatro motivos generales que han generado críticas hacia las santificaciones recientes.

29 Sergio Zaldívar, "Los beatos de Oaxaca", Proceso, el 27 de julio de 2002, https://www.proceso.com.mx/187969/los-beatos-de-oaxaca.

30 Bernardo Barranco, "Canonización y polémica del 'niño cristero", Milenio, el 19 de octubre de 2016, http://www.milenio.com/opinion/bernardo-barranco/posteando/canonizacion-y-polemica-del-nino-cristero.

31 "Polémica en México sobre la aparición de la Virgen de Guadalupe", El País, el 31 de mayo de 1996.

32 "Canonización calculada", Proceso, el 15 de octubre de 2006.

Sillares, vol. 1, núm. 2, 2022

DOI: https://doi.org/10.29105/sillares1.2-5 
Primeramente, algunos cuestionan su copiosidad, producto de la "simplificación" del proceso que decretó Juan Pablo II en 1983 donde, principalmente, se redujo el número de milagros exigidos de cuatro (dos para la beatificación y dos para la canonización) a sólo dos y se eliminó la figura del promotor de la fe o advocatus diaboli.

En segundo lugar, como ya se había mencionado en relación con los mártires de la Cristiada, se critica que ha habido "demasiados sacerdotes y monjas y no suficientes personas laicas con quienes los católicos promedio pudieran relacionarse más fácilmente". En tercera instancia, "algunas canonizaciones y beatificaciones también parecen sólo políticamente motivadas", por ejemplo, es el caso de algunos mártires de regímenes condenados por la Iglesia, como los socialistas. ${ }^{33}$

Y, por último, se ha criticado duramente el predominio del factor económico en los procesos, por encima de lo estrictamente religioso. Así, en 2015 los periodistas italianos Gianluigi Nuzzi y Emiliano Fittipaldi denunciaron en sus respectivos libros (sustentados en documentación vaticana) "que las beatificaciones y santificaciones no se basan en los supuestos milagros que ha realizado el interesado, sino en el dinero que se paga a la Santa Sede”. Según Nuzzi, “[e]1 coste es de alrededor de medio

33 Melinda Henneberger, "Ideas \& trends; the Saints just keep marching in", New York Times, el 16 de julio de 2018, https://www.nytimes.com/2002/03/03/ weekinreview/ideas-trends-the-saints-just-keep-marching-in.html. [La traducción ha sido realizada por el autor de esta investigación.]

Sillares, vol. 1, núm. 2, 2022

207

DOI: https://doi.org/10.29105/sillares1.2-5 
millón de euros de media", por lo que denunció que "dichos procedimientos son una auténtica máquina de hacer dinero". Estas críticas motivaron al papa Francisco a decretar en marzo de 2016 estrictos controles financieros de los recursos que fluyen durante los procesos de canonización, con el fin de que se destinen únicamente a los gastos de las causas, y a establecer un "fondo de solidaridad" para sustentar la fase romana del proceso, de manera que la carencia de recursos económicos no sea un obstáculo para su avance. ${ }^{34}$

Al margen de las polémicas, México cuenta con alrededor de cien procesos de canonización promovidos por las diversas diócesis del país, siendo las más importantes las Arquidiócesis de México y Guadalajara. Por su parte, la Iglesia regiomontana ha presentado particularidades en este aspecto y sólo ha incoado cinco causas, como se verá enseguida.

\section{Procesos de canonización neoleoneses}

Durante la época virreinal, hubo diversos religiosos destacados en el Nuevo Reino de León. Tal fue el caso del misionero fray Martín de Altamirano, uno de los fundadores del convento de San Andrés en Monterrey, quien murió martirizado en 1606 flechado por un grupo indígena en la Pastora. Asimismo, hubo importantes

\footnotetext{
34 Mònica Bernabé, "El Papa reforma los procesos de canonización para asegurar su transparencia financiera", El Mundo, el 10 de marzo de 2016, http://www.elmundo.es/sociedad/2016/03/10/56e1a17422601d031a8b45b7. $\underline{\mathrm{html}}$.

Sillares, vol. 1, núm. 2, 2022

208

DOI: https://doi.org/10.29105/sillares1.2-5
} 
religiosos protectores de los indígenas, como fray José de San Gabriel en las misiones del Río Blanco, hacia 1650; fray Antonio Margil de Jesús, quien fundó un hospital y escuela en Boca de Leones alrededor de 1715; y fray Juan de Losada, quien fue activo en Linares y el Valle del Pilón hacia $1715 .{ }^{35}$ Sin embargo, sólo fue introducida la causa de canonización de uno de estos religiosos: fray Antonio Margil por parte del Arzobispado de México en 1767, quien fue declarado venerable en 1836, pero desde entonces su proceso se estancó. ${ }^{36}$

Por otro lado, los habitantes del Nuevo Reino de León, al igual que el resto de los novohispanos, al carecer de santos propios encontraron a quien venerar en los santos e imágenes religiosas. ${ }^{37}$ Así, en el acta de fundación de Monterrey se estipuló que la iglesia mayor debía dedicarse a la Virgen María en "su Santa y Limpia Concepción y Anunciación", ${ }^{38}$ y con el correr de los años se agregaron otras imágenes y advocaciones marianas, como la Virgen del Reino, del Nogal o del Roble, sustentada en

35 Cavazos Garza, Breve historia de Nuevo León, 1994, 31-38.

36 Antonio Rubial García, La santidad controvertida: Hagiografía y conciencia criolla alrededor de los venerables no canonizados de Nueva España (México, DF: Universidad Nacional Autónoma de México; Fondo de Cultura Económica, 2015).

37 Maribel García Méndez, "Credibilidad y opinión pública entre estudiantes de Ciencias de la Comunicación y Derecho: Caso la Iglesia Católica" (Universidad de las Américas Puebla, 2004), 44, http://catarina.udlap.mx/u dl_a/tales/documentos/lco/garcia_m_m/ capitulo3.pdf.

38 "Acta de fundación de Monterrey. Anexo núm. 1", consultado el 16 de julio de 2018, http://cdigital.dgb.uanl.mx/la/1020110039/1020110039.PDF.

Sillares, vol. 1, núm. 2, 2022

DOI: https://doi.org/10.29105/sillares1.2-5 
una leyenda del siglo XVII; ${ }^{39}$ la Virgen de la Purísima, con base en un supuesto milagro de $1716,{ }^{40} \mathrm{y}$ la Virgen de Guadalupe, cuya devoción arraigó en la primera mitad del siglo XVIII. También hubo devoción importante hacia los santos franciscanos, como san Francisco y san Antonio, y hacia los santos patronos de los poblados del reino, como san Gregorio Magno, santa Catarina, san Pedro, Santiago y san Juan Bautista. Además, al carecer de causas locales de canonización, durante el siglo XVIII los habitantes de la región apoyaban frecuentemente en sus testamentos al proceso del cardenal Cisneros. ${ }^{41}$

Durante el siglo XIX se agregaron otras devociones, como la de san Caralampio (santo patrono contra la peste), a quien se erigió una capilla en Monterrey que existió de 1830-1846, ${ }^{42}$ y a santa Rita, a quien se dedicó también un efímero templo. ${ }^{43}$ Además, para fines del siglo un sacerdote regiomontano obtuvo en Roma una reliquia importante: el cráneo de santa Librada,

39 Israel Cavazos Garza, Crónicas y sucedidos del Monterrey virreinal (Monterrey: Universidad Autónoma de Nuevo León - Facultad de Filosofía y Letras, 2009), 144-48.

40 Santiago Roel, Nuevo León. Apuntes históricos (Monterrey: Castillo, 1980), 57.

41 Rodríguez, entrevista.

42 Enrique Tovar Esquivel y Adriana Patricia Garza Luna, "La capilla de San Caralampio. Una presencia fugaz en Monterrey", Boletín de monumentos históricos, núm. 6 (2006): 19-26, https://revistas.inah.gob.mx/index.php/boletinmonumentos/article/view/1996/1926.

43 Abraham Vázquez, "El historiador y cronista Carlos González y los arqueólogos Aracely Rivera y Enrique Tovar trazan aquí esta cartografía de lugares de ayer", El Norte, el 12 de mayo de 2008.

Sillares, vol. 1, núm. 2, 2022

DOI: https://doi.org/10.29105/sillares1.2-5 
que se depositó en la parroquia de La Luz. ${ }^{44} \mathrm{Y}$ en 1924, tras su visita a Roma, el arzobispo José Juan de Jesús Herrera y Piña llevó a Monterrey dos reliquias más: las de san Teófimo y santa Irene, las primeras depositadas en el Seminario y las segundas concedidas a las Misioneras Catequistas de los Pobres. ${ }^{45}$ Así, ante la carencia de santos propios, la población orientó su devoción hacia estos santos poco conocidos, pero de quienes se contaba con sus reliquias autenticadas por Roma.

No obstante, también surgieron figuras de santos populares, no avalados por la Iglesia, como el taumaturgo El Tatita (década de 1860) ${ }^{46}$ y el Niño Fidencio (1898-1938), reconocido por sus seguidores como un "médico-vidente-rey-pontífice". ${ }^{47}$ Así, al margen de la ortodoxia católica, la devoción popular suplantó la ausencia de santos locales con estas figuras sagradas. Sin embargo, durante la primera mitad del siglo XX y hasta los años 60 también destacaron en Monterrey algunos personajes

\footnotetext{
44 Aunque esta reliquia se asocia con la legendaria santa Librada o Wilgefortis, una santa barbuda que fue crucificada según la leyenda medieval, este cráneo al parecer provenía de las catacumbas romanas, por lo que pudo tratarse de alguna mártir de los primeros siglos del cristianismo. Ver Luis Barrera López, "Reviven reliquias de Santa Librada", El Mañana, el 10 de marzo de 2018, http://www.elmanana.com.mx/noticia/97178/Reviven-reliquias--de-Santa-Librada.html.

45 Vicente Guerrero, "Santos entre los regios", El Norte, el 4 de febrero de 2001, https://norte-monterrey.vlex.com.mx/vid/santos-regios-78203979.

46 Roel, Nuevo León. Apuntes históricos, 180-81.

47 Israel Cavazos Garza, Breve historia de Nuevo León (México, DF: El Colegio de México; Fideicomiso Historia de las Américas; Fondo de Cultura Económica, 2003), 201-2.
}

Sillares, vol. 1, núm. 2, 2022

DOI: https://doi.org/10.29105/sillares1.2-5 
religiosos que se ganaron la veneración popular, quienes por su carisma y labor pastoral se hallan actualmente en proceso de canonización. A continuación se expondrá un esbozo sobre la vida de estos personajes, así como en torno a la introducción y estado actual de sus procesos de canonización.

\section{Juan José Hinojosa Cantú}

Nació el 24 de noviembre de $1874^{48}$ en Agualeguas, Nuevo León; sus padres fueron los señores Silvestre Hinojosa y Agapita Cantú de Hinojosa. Cursó su instrucción primaria en Monterrey y la preparatoria en el Colegio de San Juan Nepomuceno de Saltillo. Entre 1889 y 1891 realizó sus estudios sacerdotales en el Seminario Conciliar de Guadalajara, y luego pasó al Seminario de Monterrey. Fue ordenado sacerdote en diciembre de 1897 en la Catedral de Monterrey por el arzobispo Jacinto López y Romo. En mayo de 1898 fue designado vicario de la Capilla del Sagrario de Catedral y en abril de 1900 fue nombrado director de la Asociación de la Santa Infancia del Colegio de San José.

Desde enero de 1901 se desempeñó como maestro y director espiritual del Seminario de Monterrey, de donde fue designado vicerrector en 1904. Tres años después, en 1907, comenzó bajo su iniciativa la publicación del semanario de propaganda católica denominado "Hoja dominical". En noviembre de ese mismo año fue nombrado secretario de la

48 Algunas fuentes ubican erróneamente su nacimiento en 1871.

Sillares, vol. 1, núm. 2, 2022

DOI: https://doi.org/10.29105/sillares1.2-5 
Mitra por el arzobispo Leopoldo Ruiz y Flores, y en diciembre impulsó el inicio de otra publicación: el "Boletín Eclesiástico de la Provincia Arquidiocesana".

Posteriormente, en mayo de 1917 fundó la Congregación Mariana de María Inmaculada y San Luis Gonzaga con un grupo de adolescentes, con el objetivo de forjar en ellos bases morales y espirituales, con "el espíritu de los verdaderos apóstoles de Cristo"; más delante, esta asociación se denominó Congregación Mariana de El Roble. Ese mismo año, el Seminario pasó a ubicarse en un anexo del templo de El Roble, donde también ejerció su ministerio el padre Hinojosa.

En 1919 fundó la Asociación Católica de la Juventud Mexicana en Monterrey, con miembros de las Congregaciones Marianas, y en 1920 fue designado para ocupar nuevos cargos: primer tesorero de la Sociedad Mutualista de Sacerdotes, tesorero de la Mitra, consultor diocesano, notario del Tribunal eclesiástico y secretario de la Dirección General del Apostolado de la Oración y demás asociaciones que tenían como objetivo el culto al Sagrado Corazón.

En diciembre de 1921 el arzobispo Herrera y Piña lo designó canónigo, como miembro del Cabildo de Catedral. Pero en septiembre de 1923 renunció como secretario de la Mitra, debido a su carga de trabajo y por motivos de salud, aunque continuó desempeñándose como tesorero. Ese mismo año, tras la erección del templo de San Luis Gonzaga, ejerció su labor Sillares, vol. 1, núm. 2, 2022 
sacerdotal en este recinto. Tiempo después, en junio de 1930 fue nombrado delegado diocesano de la Liga Sacerdotal Mexicana, y para mayo de 1933 el papa lo designó deán de la Catedral.

Se afirma que "[e]ra tan intensa su fe ardiente en la presencia de Cristo en la Sagrada Eucaristía que inolvidables veces lo llevó al éxtasis y la levitación al momento de la consagración". El padre Hinojosa falleció el 10 de diciembre de 1935 y su cuerpo fue velado en un anexo de la Catedral, adonde acudieron numerosas personas para rendirle homenaje. Al día siguiente fue sepultado en el panteón de El Carmen, pero en 1967 sus restos fueron trasladados a la cripta de la Capilla de San José, anexa al templo de El Roble. ${ }^{49}$

Las Congregaciones Marianas siempre promovieron la vida y virtudes del padre Hinojosa, y en octubre de 1983 solicitaron formalmente al arzobispo José de Jesús Tirado y Pedraza que se diera inicio al proceso de canonización de su fundador. Así, comenzó la recopilación de testimonios y documentos, y en agosto de 1991 el arzobispo Adolfo Suárez Rivera integró el Tribunal ad causam, con la Congregación Mariana de El Roble como actor y el señor José Ortiz Bernal como postulador. El proceso diocesano concluyó en noviembre de 1994, remitiéndose la causa a Roma, donde en mayo de 1995 se reconoció su validez. En 1994 el señor Ortiz Bernal publicó una obra biográfica sobre el fundador de las Congregaciones

49 "Biografía y resumen cronológico", Causa Padre Juan José Hinojosa Cantú, 2018, http://www.causapadrejuanjosehinojosacantu.com.mx/biografia-delsiervo-de-dios-cngo--juan-jose-hinoj_1.html.

Sillares, vol. 1, núm. 2, 2022

DOI: https://doi.org/10.29105/sillares1.2-5 
Marianas, quien ostenta el título de siervo de Dios y cuyo proceso no ha tenido mayores avances tras su introducción en El Vaticano. ${ }^{50}$

\section{Raymundo Jardón Herrera}

Vio la luz en Tenancingo, Estado de México, en 1887. Sus padres fueron los señores Jacinto Jardón y Paula Herrera. Trabajó desde pequeño para ayudar a su familia y luego ingresó al Colegio Pío Gregoriano de Tenancingo, con la ayuda del párroco de su pueblo. Posteriormente, pasó al Seminario de San José de Cuernavaca, donde se convirtió en "familiar" del obispo de la diócesis, Francisco Plancarte y Navarrete, es decir, éste asumió el papel de tutor del joven seminarista. Y, cuando en 1912 el prelado fue trasladado al arzobispado de Linares-Monterrey, lo acompañó Raymundo Jardón junto con otros dos seminaristas para cursar en Monterrey la última etapa de su formación sacerdotal. ${ }^{51}$ El 27 de abril de 1913 fue ordenado sacerdote en la Catedral de Saltillo por el obispo Jesús María Echavarría, debido a que monseñor Plancarte se hallaba enfermo.

Tras convertirse en presbítero, fue nombrado sacristán mayor de la Catedral de Monterrey, cargo en el que permaneció hasta su muerte. Destacó por ser un sacerdote abocado hacia la predicación, la confesión, la catequesis y la visita a los enfermos. ${ }^{52}$

50 "Biografía y resumen cronológico".

51 "Infancia y vocación”, Causa de beatificación y canonización, 2018, https://www.padrejardon.org.mx/.

52 Hermes Campos, El mundo del Padre Raymundo (Monterrey: Sociedad de Amigos del Padre Jardón, 2000), 31-33.

Sillares, vol. 1, núm. 2, 2022

DOI: https://doi.org/10.29105/sillares1.2-5 
Fue fundador de diversos movimientos y asociaciones parroquiales, y apoyó a grupos de damas como la Asociación San Vicente de Paul, la Asociación del Santísimo y la Asociación de Damas Católicas Mexicanas. Además, coincidiendo con la labor del padre Hinojosa, fundó en 1918 la Congregación Mariana en la Catedral y participó en el establecimiento de la Asociación Católica de la Juventud Mexicana en Monterrey en 1919. ${ }^{53}$ Fue gran promotor del culto guadalupano, iniciando las peregrinaciones a dicho Santuario en 1922 y mandando pintar la imagen que se ubica actualmente en ese templo. ${ }^{54}$ Durante la época de la persecución religiosa, partió al exilio desde marzo de 1927, acompañando al arzobispo Leopoldo Ruiz y Flores en Estados Unidos y Cuba, y regresó a Monterrey a principios de $1928 .{ }^{55}$

Como responsable de la Catedral, emprendió algunas labores de remodelación y construcción, y atendió también a la Capilla de Guadalupe en la villa homónima. ${ }^{56}$ En 1930 organizó a la Acción Católica en Monterrey, tras la disposición papal al respecto.$^{57}$ En 1933 el gobierno le prohibió el ejercicio sacerdotal e incluso hubo intentos de aprehenderlo, por lo que debió continuar su ministerio de manera clandestina. ${ }^{58}$ El padre Jardón falleció el 6 de enero de 1934 y su funeral fue apoteósico, pues pese al cli-

\footnotetext{
53 Campos, 39-42.

54 "Infancia y vocación".

55 Campos, El mundo del Padre Raymundo, 67-70.

56 Campos, 37.

57 Campos, 43.

58 Campos, 60, 61 y 73.
}

Sillares, vol. 1, núm. 2, 2022

DOI: https://doi.org/10.29105/sillares1.2-5 
ma de tensión religiosa su cortejo contaba con miles de personas, más de 300 vehículos y cubría más de veinte cuadras. ${ }^{59}$

Fue sepultado en el panteón de El Carmen, pero en 2002 sus restos fueron trasladados a la cripta de la Catedral de Monterrey. Según se afirma, han aparecido diariamente flores frescas en su tumba del panteón (incluso después de 2002) durante casi 85 años. ${ }^{60} \mathrm{Se}$ le han rendido cuando menos dos homenajes públicos: en 1985 se develó una estatua suya en el atrio de la Catedral, en presencia del gobernador Alfonso Martínez Domínguez, y en 1995 el Cabildo de Monterrey aprobó cambiar el nombre de la calle Ocampo, en su tramo de Zuazua a Constitución, por el de Padre Raymundo Jardón. ${ }^{61}$

De tal modo, la memoria de este sacerdote pervivió en la sociedad católica regiomontana e incluso se organizó el "Grupo de Amigos del Padre Jardón", integrado por sacerdotes y laicos, para promover su causa de canonización. Como resultado de sus gestiones, el arzobispo Suárez instituyó en agosto de 1987 el Tribunal ad causam, en el mismo decreto donde se conformó el del padre Hinojosa. El actor fue el mencionado Grupo de Amigos y el postulador el padre Carlos Álvarez. En mayo de 1991 se abrió la causa diocesana; ese mismo año, Hermes Campos, miembro del Grupo de Amigos, publicó un texto biográfico sobre el padre Jardón. La etapa diocesana del proceso se clausuró en noviembre de 1994.

\footnotetext{
59 Campos, 80-81 y 91-92.

60 Campos, 95.

61 "Infancia y vocación".
}

Sillares, vol. 1, núm. 2, 2022 
En octubre de 1995 la Congregación para las Causas de los Santos reconoció la validez del proceso y en 1999 se emitió la Positio. Posteriormente, en octubre de 2015 se reunieron los censores teólogos y, más adelante, la junta de cardenales y obispos revisó y aprobó la causa. Así, el 20 de enero de 2017 el papa Francisco promulgó el decreto que reconoce las virtudes heroicas del padre Jardón, quien pasó a ser designado como venerable. Su causa es la que ha tenido mayor avance de las que se promueven desde la arquidiócesis regiomontana y sólo se requiere un milagro para que pueda ser declarado beato. ${ }^{62}$

\section{Pablo Cervantes Perusquía}

Originario de Amealco, Querétaro, donde nació el 15 de enero de 1891. Fue hijo de los señores Eduardo Cervantes y María Perusquía. En 1901, su padre lo inscribió en el Seminario diocesano, pero debió suspender sus estudios en 1909 por motivos de salud. Entretanto, el arzobispo de Linares-Monterrey, Leopoldo Ruiz y Flores, quien también era oriundo de Amealco, visitó dicho poblado donde conoció al joven Pablo y lo animó a continuar sus estudios en Monterrey. Así, se reincorporó a los estudios sacerdotales y en 1910 fue enviado a Roma, donde ingresó a la Pontificia Universidad Gregoriana. El 11 de abril de 1914 fue ordenado sacerdote en Roma, y poco después recibió el grado de Doctor en Teología. En septiembre

62 Hagiography Circle", consultado el 3 de octubre de 2018, http://newsaints. faithweb.com/.

Sillares, vol. 1, núm. 2, 2022

DOI: https://doi.org/10.29105/sillares1.2-5 
de ese mismo año regresó a México y arribó a Monterrey en febrero de 1917.

Una vez asentado en la arquidiócesis regiomontana, fue nombrado capellán de las religiosas del Verbo Encarnado y párroco del templo de Santa Catarina, en el municipio homónimo, cargo que ejerció hasta junio de 1918. Posteriormente, fue incorporado al Seminario de Monterrey, donde fungió como maestro de matemáticas, latín, lengua española, geografía, lógica, ética, sociología pastoral, acción católica y teología dogmática. Fue luego designado capellán, prefecto de disciplina, prefecto de estudios, vicerrector y ecónomo en el mismo Seminario. Al igual que los padres Hinojosa y Jardón, participó en 1919 en la conformación de la Asociación Católica de la Juventud Mexicana en Monterrey. En 1920 se multiplicaron sus cargos: fue designado secretario de la Sociedad Mutualista de Sacerdotes, promotor fiscal y examinador prosinodal de la curia, capellán del Colegio María Auxiliadora de las religiosas Salesianas, segundo secretario de las conferencias mensuales del clero y prosecretario de la Mitra.

Un año después, fue nombrado capellán de la Orden de los Caballeros de Colón, a quienes impartía formación en los Círculos de Estudios Sociales que se realizaban semanalmente. En 1922 fue designado fiscal y censor de la Mitra, así como canónigo del Cabildo de la Catedral, y ese mismo año creó la Unión Profesional de Empleadas Católicas. Entre 1923 y 1930 Sillares, vol. 1, núm. 2, 2022 
fue asistente eclesiástico de la Unión de Damas Católicas Mexicanas. Durante el período de la suspensión de cultos (19261929), residió junto con otros sacerdotes en una casa particular, y salía disfrazado de civil para desempeñar su ministerio sacerdotal e impartir clases a los seminaristas.

En 1930, al igual que el padre Jardón, impulsó la creación de los organismos diocesanos y de los grupos parroquiales de Acción Católica, y en 1933 fue fundador del primer comité de la Unión de Católicos Mexicanos en Monterrey, y fungió como asistente eclesiástico de estos grupos. Asimismo, creó la Escuela de Dirigentes, para formar a los responsables del apostolado seglar, y en 1937 creó la Liga de Hombres de Eucaristía, para promover la vida eucarística entre los jóvenes.

En 1941, el arzobispo Guillermo Tritschler lo nombró secretario de cámara y gobierno de la arquidiócesis. En los años siguientes continuó trabajando en la creación de asociaciones del catolicismo social, como las siguientes: las Hermanas del Servicio Social en 1944; el instituto secular Discípulas del Señor en 1945; el Centro Obrero de Estudios Sociales (a partir de esta asociación se puso atención al problema de la carencia de vivienda, y el padre Cervantes impulsó la creación de la colonia León XIII); una casa hogar para empleadas y estudiantes, y la asociación Solidaridad Femenina (emanada de la Unión Profesional de Empleadas Católicas) en 1947; el Centro Cultural Lumen en 1948; y la Escuela de Trabajo Social, en la Clínica y Maternidad Conchita, Sillares, vol. 1, núm. 2, 2022 220 DOI: https://doi.org/10.29105/sillares1.2-5 
entre otras. El padre Cervantes falleció el 7 de abril de 1956 y fue sepultado en el panteón de El Roble; sin embargo, en 1977 sus restos fueron trasladados a la cripta de la Basílica de El Roble. ${ }^{63}$

El recuerdo y respeto hacia la figura del padre Cervantes se mantuvieron vivos en Monterrey; así, se publicaron obras biográficas-hagiográficas en 1961 y 1971, a cargo de los sacerdotes Isaac Hernández y Aureliano Tapia Méndez, respectivamente. No obstante, su causa de canonización no inició sino hasta 1994, a petición de la Congregación Discípulas del Señor y del Centro Cultural Lumen, y bajo el respaldo del arzobispo Suárez. El proceso fue relativamente rápido y para 1996 pasó a Roma, donde se decretó su validez en noviembre de ese año. Ostenta el título de siervo de Dios y su causa no ha tenido posteriores avances. ${ }^{64}$

\section{Guillermo Tritschler y Córdova}

Nació en San Andrés Chalchicomula (hoy Ciudad Serdán), Puebla, el 6 de julio de 1878, siendo sus padres el señor Martín Tritschler, inmigrante alemán y próspero relojero, y la señora Rosa María Córdova y Puig. Su educación inicial estuvo a cargo de su tío Prisciliano Córdova, quien era sacerdote y lo envió en una peregrinación a Roma en 1888; en dicha ciudad, ingresó al Colegio Pío Latinoamericano junto con sus hermanos Martín y

63 "Causas de canonización en Arquidiócesis de Monterrey", consultado el 19 de julio de 2018, http://www.arquidiocesismty.org/causas-de-canonizacion. php. Aureliano Tapia Méndez, Pablo Cervantes, un sacerdote de su tiempo (México, DF: Jus, 1971).

64 "Hagiography Circle".

Sillares, vol. 1, núm. 2, 2022

DOI: https://doi.org/10.29105/sillares1.2-5 
Alfonso. En agosto de 1902 regresó a México, habiendo recibido tres doctorados: en Filosofía, Teología y Derecho Canónico.

Fue ordenado sacerdote el 19 de junio de 1904 en la capilla del palacio arzobispal de Puebla por su hermano Martín, quien ya era obispo de Yucatán desde 1900. Posteriormente, le fueron encomendadas diversas labores académicas: profesor en el Seminario Conciliar de México (desde 1905), catedrático en la Universidad Pontificia Mexicana (a partir de 1911) y padre espiritual del Seminario de Regina (desde 1916). En 1929 el arzobispo de México, Pascual Díaz, lo designó canónigo penitenciario de la Catedral.

En 1931 el papa Pío XI lo nombró obispo de San Luis Potosí. Y aunque inicialmente se negó, argumentando que carecía de habilidades para predicar, escribir, ejercer autoridad, regañar y manejar dinero, sus objeciones fueron ignoradas y el 22 de abril recibió la consagración episcopal de manos de su hermano Martín, en la Basílica de Guadalupe de la Ciudad de México. Como obispo de San Luis Potosí restableció las prácticas religiosas suspendidas por la persecución religiosa, elevó el número y la preparación de los seminaristas, fortaleció las asociaciones católicas, e impulsó la construcción del templo de Matehuala, entre otras obras. Debido a sus conocimientos de Bellas Artes, en 1940 fue nombrado miembro de la Academia Mexicana de la Historia.

Entretanto, el arzobispo de Monterrey, José Guadalupe Ortiz y López, renunció a su cargo en 1940 al cumplir 50 años Sillares, vol. 1, núm. 2, 2022 DOI: https://doi.org/10.29105/sillares1.2-5 
de sacerdote, y el papa Pío XII designó a monseñor Guillermo Tritschler para sucederlo, quien arribó a su nueva arquidiócesis en junio de 1941. Emprendió la construcción de grandes templos, como los de La Purísima y Cristo Rey, remodeló el presbiterio de la Catedral y celebró en 1945 un Congreso Guadalupano. Impulsó de manera particular al Seminario, pues reconocía la carencia de sacerdotes; así, logró más que duplicar el número de seminaristas y en 1948 envió a algunos a Roma y a Montezuma, en Estados Unidos. En 1950 enfermó durante un vuelo a Madrid, camino a Roma para entrevistarse con el papa. En mayo de 1951, monseñor Alfonso Espino y Silva fue designado como obispo coadjutor, debido a los problemas de salud del arzobispo Tritschler.

Falleció el 29 de julio de 1952 en su residencia en los anexos del templo de El Roble, acompañado por monseñor Espino, el padre Cervantes y dos seminaristas; miles de personas acudieron a sus funerales y fue sepultado en la Catedral de Monterrey. Según se afirma, cuando se hallaba agonizante se derramó su sangre en unos algodones y ésta permaneció fresca durante varios días después de su muerte. Asimismo, diversos testimonios sostienen que cuando su cuerpo fue exhumado en 1964 (para ser depositado en la cripta de los arzobispos en la misma Catedral), fue hallado "como si acabara de fallecer", lo cual se consideró un hecho prodigioso, aunque se reconoció que su cadáver fue desangrado y embalsamado previo al sepelio. ${ }^{65}$

65 Gustavo Velarde, Los Arzobispos Martín y Guillermo Tritschler y CórdoSillares, vol. 1, núm. 2, 2022

DOI: https://doi.org/10.29105/sillares1.2-5 
En 1956, cuatro años después del fallecimiento del arzobispo Tritschler, monseñor Arturo Vélez Martínez, obispo de Toluca, promulgó una exhortación donde elogiaba las virtudes del prelado regiomontano y promovía su elevación a los altares. En 1965, monseñor Gregorio Aguilar, deán de la Basílica de Guadalupe de la Ciudad de México, encomendó al padre Porfirio Valadés la publicación de una obra biográfica que tenía la intención de contribuir a la causa de canonización de don Guillermo. En marzo de 1979 el arzobispo de Monterrey, monseñor Tirado y Pedraza, promulgó un edicto que integró una comisión e iniciaba labores para el proceso diocesano. No obstante, este intento se vio interrumpido sin mayores avances. No fue sino hasta agosto de 1987 cuando el arzobispo Suárez Rivera instauró formalmente el Tribunal ad causam (en conjunto con los de los padres Hinojosa y Jardón), fungiendo como actor el presbiterio de Monterrey, con el padre Rogelio Martínez Berrones como postulador.

Sin embargo, la marcha de la causa fue lenta. El proceso diocesano se inició oficialmente en febrero de 1991, pero en mayo de 1996 debieron ser sustituidos todos los miembros del Tribunal. Finalmente, la etapa diocesana se clausuró en julio de 1997, cuando la causa fue remitida a Roma; poco después, se reconoció su validez. En torno a esta época, en

va. Semblanza biográfica y genealógica (Puebla: Mercadeo Múltiple División Editorial, 2008), 247-319, https://issuu.com/gustavovelarde-tritschler/docs/ los_arzobispos_mart n_y guillermo 336496fca742d3.

Sillares, vol. 1, núm. 2, 2022

224

DOI: https://doi.org/10.29105/sillares1.2-5 
1998 monseñor Aureliano Tapia Méndez, perito en Historia y Archivística del Tribunal de la causa, publicó una nueva obra biográfica sobre el arzobispo Tritschler, quien recibió el título de siervo de Dios. El proceso no ha tenido mayores avances hasta la fecha. ${ }^{66}$

\section{Gloria Esperanza Elizondo García}

Era originaria de la capital del estado de Durango, donde vio la luz el 26 de agosto de 1908, siendo sus padres los señores Alberto Elizondo González y Otilia García Peña. Desde los 4 años comenzó a acudir al colegio, pero su familia debió emigrar hacia Monterrey durante la Revolución; en esta ciudad continuó sus estudios y se graduó de Teneduría de Libros en 1921. Trabajó en algunas empresas pequeñas, y se aficionó también por el dibujo y la pintura, llegando a impartir clases de estas actividades. Asimismo, desde 1928 realizó trabajo de apostolado, visitando a los enfermos mentales del Hospital González y a los presos de la Penitenciaría del estado.

En 1940 se enteró de que en Ciudad Victoria, Tamaulipas, existía una empacadora de la Escuela Normal Rural que se ofrecía en renta, y decidió trasladarse a dicha ciudad y tomar las riendas de ese negocio, al que nombró "Productos Cruz de Oro". Continuó su apostolado en este lugar, con los trabajadores y vecinos de la ciudad, motivándolos a ingresar a la Acción Católica, organizando

\footnotetext{
${ }_{66}$ Velarde, 247-53.
}

Sillares, vol. 1, núm. 2, 2022

DOI: https://doi.org/10.29105/sillares1.2-5 
conferencias para profesionistas y maestros, realizando mesas redondas para matrimonios, impulsando la impartición del Catecismo a los niños, e incluso sustentó la fundación de un colegio en 1943 y emprendió la construcción de un templo, que fue consagrado en 1948. Una prioridad de su labor fue la atención a las mujeres, para las que creó un taller de oficios, y a las desamparadas o prostitutas las trasladaba a Monterrey con las Madres del Buen Pastor, aunque en 1943 logró que estas religiosas instalaran una comunidad en Ciudad Victoria para la atención de las mujeres.

En 1950, Gloria regresó a Monterrey y pasó a trabajar con su familia en la empresa Elizondo S.A., donde ella comenzó a organizar reuniones, misas y convivencias para evangelizar a los trabajadores. Sin embargo, en 1954 decidió abrazar la vida religiosa e ingresar a la Congregación de las Misioneras Catequistas de los Pobres. En 1956 publicó su libro Jesucristo, que tuvo varias ediciones posteriores, cuyas ganancias dedicó a obras de beneficencia y de apoyo a organizaciones del catolicismo social, como la Juventud Católica Femenina Mexicana y los Caballeros de Colón. En abril de 1957 hizo su primera profesión de votos, tomando el nombre de sor Gloria María de Jesús, y en 1959 fue nombrada maestra de postulantes. Para mayo de 1961 fue designada Superiora General de la Congregación, y poco después hizo su profesión de votos perpetuos. Además de atender los asuntos de su comunidad religiosa, tuvo la iniciativa de emprender los Cursillos de Cristiandad para Damas en 1962.

Sillares, vol. 1, núm. 2, 2022 
Desde 1965 enfermó de cáncer y falleció el 8 de diciembre de 1966. Sus exequias fueron presididas por el arzobispo Alfonso Espino y Silva en la capilla del convento Villa de la Paz y sus restos fueron depositados en el panteón de El Carmen. Las religiosas afirmaron que al instante de su muerte en el hospital vieron deshojarse una flor en el altar de la capilla del convento, donde se hallaban en oración. ${ }^{67}$ Asimismo, su familia sostuvo que, después de su fallecimiento, recibió por parte de dos religiosas (que luego se supo que no eran del convento y que nadie las conocía) el anillo de sor Gloria, pese a que ella nunca permitió que se lo retiraran de su mano antes de morir. ${ }^{68}$

La Congregación de las Misioneras Catequistas de los Pobres, de la cual fue Superiora General, promovió la elevación a los altares de la hermana Elizondo. En 1993 se iniciaron los procedimientos para introducir su causa de canonización, con la anuencia del arzobispo Suárez. En febrero de 1995 se inició el proceso diocesano, que culminó en octubre del mismo año, remitiéndose la causa a Roma, donde se decretó su validez en mayo de 1996. Sor Gloria es reconocida como sierva de Dios y en 2005 se emitió la Positio, tras lo cual el proceso no ha tenido nuevos avances. ${ }^{69}$

67 Sierva de Dios Sor Gloria María Elizondo García, Misionera Catequista de los Pobres (Monterrey: Congregación Misioneras Catequistas de los Pobres, s/f), 1-30.

68 Martínez, entrevista.

69 "Hagiography Circle".

Sillares, vol. 1, núm. 2, 2022

DOI: https://doi.org/10.29105/sillares1.2-5 


\section{Interpretación en torno a los procesos de canonización neoleoneses}

Se pueden atisbar algunos factores interpretativos con relación a los motivos y el sentido de las escasas causas de canonización que ha promovido la Arquidiócesis de Monterrey. En primera instancia, el catolicismo neoleonés manifestó, desde la época virreinal, un arraigo relativamente débil y pragmático, pues la religiosidad no ocupó una parte axial en la vida social. Al respecto, un documento del Secretariado Social Arquidiocesano publicado en 1981 afirmaba que "puede decirse que la sociedad norteña es más secularizada que la del resto del país", y ello le impide al habitante de dicha región "vivir una religiosidad similar a la del mexicano del centro y el sur", por lo que al norteño se le atribuye frialdad en su fe y una casi nula religiosidad. ${ }^{70}$

Pueden citarse también los testimonios de dos obispos regiomontanos que se quejaban de la presunta incultura de sus feligreses. El primero de ellos corresponde al prelado Primo Feliciano Marín de Porras (1803-1815), quien afirmaba en 1813 sobre la población neoleonesa que "son inútiles las fatigas del obispo en procurar su ilustración, ni mejorar de ideas", porque su ocupación en asuntos mundanos "les alejan muchísimo de las grandes ideas de estudio e ilustración". ${ }^{71}$ Décadas más tarde, el

70 Aurelia Guadalupe Sánchez Morales, Virginia Saro Serrato, y Ángel Tello Hernández, Arquidiócesis de Monterrey, N. L., México. Investigación estadística y documental (Monterrey: Secretariado Social Arquidiocesano, 1981), 12-14.

71 Citado por: Israel Cavazos Garza, "La educación en Nuevo León, en 1813. Informe del Obispo Don Primo Feliciano Marín de Porras sobre el Seminario Sillares, vol. 1, núm. 2, 2022

DOI: https://doi.org/10.29105/sillares1.2-5 
obispo Ignacio Montes de Oca y Obregón (1879-1883) se quejaba del poco respaldo de sus feligreses, que hizo cesar "todo amor de mi parte hacia ellos". ${ }^{72}$ Y criticaba a la "inculta Monterrey", a la que calificaba de "salvaje". ${ }^{73}$ Puede inferirse que el discurso de los prelados esbozaba una débil devoción religiosa entre sus feligreses. Por ello, es significativo que sólo uno de los cinco candidatos a los altares es originario de Nuevo León.

Por otro lado, ante las acciones persecutorias del gobierno durante la etapa revolucionaria (en especial, entre 1914 y 1917), así como en las épocas anticlericales más álgidas (1924-1936), el clero y la población neoleoneses sólo manifestaron protestas por escrito y, en general, una resistencia pasiva. Por lo anterior, no se desarrollaron levantamientos, ni tampoco mártires, e incluso los arrestos o procesos por motivos religiosos fueron mínimos, aunque sí predominó un clima tenso, donde la religiosidad pasó a la clandestinidad (con una relativa tolerancia del gobierno), y debieron partir al destierro un arzobispo (Plancarte, no así Herrera) y algunos clérigos (sobre todo, los de origen extranjero). En otras palabras, puede establecerse una correlación entre: religiosidad débil/acciones anticlericales moderadas/reacciones pasivas. ${ }^{74}$

de Monterrey", Actas. Historia, Letras y Artes (Monterrey, 1979), 9.

72 Citado por: Aureliano Tapia Méndez, El diario de Ipandro Acaico (Monterrey: Al Voleo-El Troquel, 1988), 78.

73 Citado en: Tapia Méndez, 79.

74 Moisés A. Saldaña Martínez, El anticlericalismo oficial en Nuevo León, 1924-1936 (Monterrey: Universidad Autónoma de Nuevo León - Facultad de Filosofía y Letras, 2009), 92-91, 121-52 y 173-241.

Sillares, vol. 1, núm. 2, 2022

DOI: https://doi.org/10.29105/sillares1.2-5 
No fue sino hasta finales de los años 30 , al tiempo que se forjaba el modus vivendi entre Iglesia y Estado, cuando el catolicismo consolidó su arraigo entre la población regiomontana, de la mano con su vinculación con el empresariado y con el impulso a la educación confesional. ${ }^{75}$ En este proceso, el catolicismo social fue una de las formas más palpables de la presencia social de la Iglesia, aunque sus raíces eran anteriores, remontándose a la década de $1870 .{ }^{76}$ De tal modo, destacaron algunos personajes especialmente activos en este proceso de impulso y afianzamiento del catolicismo social en Monterrey; tales fueron los sacerdotes Juan José Hinojosa, Raymundo Jardón y Pablo Cervantes, entre la segunda y la cuarta décadas del siglo $\mathrm{XX}$. Estos clérigos contribuyeron a la formación de sacerdotes en el Seminario, fundaron asociaciones de laicos y, en general, se ganaron el favor popular.

Más adelante, durante los años 40, destacó la figura del carismático arzobispo Tritschler, quien representó la restauración y ampliación de la Iglesia regiomontana tras la época persecutoria, y después de una larga etapa de debilidad y austeridad. Apoyó a las asociaciones de laicos, edificó imponentes templos y consolidó la presencia de la Iglesia en Monterrey. Fue un prelado de transición

\footnotetext{
75 Saldaña Martínez, 254-77.

76 Luis Fidel Camacho Pérez, "El catolicismo social en la Arquidiócesis de Monterrey, 1874-1926: entre el avance de la modernidad y el proyecto de restauración del orden social cristiano" (Universidad Autónoma de Nuevo León, 2017), 18-34.
}

Sillares, vol. 1, núm. 2, 2022 
y contrastes: culto y refinado, pero a la vez sencillo y humilde, incluso tímido; garante de la tradición y, al mismo tiempo, abierto a la modernidad y ajeno a radicalismos; hierático y carismático a la vez; fue, en fin, un arzobispo popular y querido por clérigos y laicos. ${ }^{77}$

Asimismo, en los años 50 y 60 la hermana Gloria fue una figura representativa del ascenso del catolicismo regiomontano, el cual permeaba el ámbito empresarial y obrero. Ella misma fue parte de dicho ambiente, e impulsora de la formación y asociación de los laicos, especialmente de las mujeres. En sus exequias, el arzobispo Espino se refirió a ella afirmando que "vivía íntimamente la vida de la gracia [...] esa vida de Dios, las virtudes sobrenaturales que poseía plenamente". ${ }^{78}$ Fue, por lo tanto, una mujer sumamente respetada por clérigos y feligreses, lo cual coadyuvó a que permaneciera en la memoria colectiva.

Así, se pone de relieve que un factor transversal en la vida de las cinco personas mencionadas fue su participación en el catolicismo social, tanto creando o atendiendo escuelas y asociaciones de laicos, como vinculándose con las élites empresariales y los obreros. Por ejemplo, "un grupo selecto de empresarios regiomontanos" sostuvo una estrecha amistad con el padre Juan José Hinojosa, desde que residía en el templo de El

77 Velarde, Los Arzobispos Martín y Guillermo Tritschler y Córdova. Semblanza biográfica y genealógica, 314-23.

78 Citado en: Sierva de Dios Sor Gloria María Elizondo García, Misionera Catequista de los Pobres, 23.

Sillares, vol. 1, núm. 2, 2022

DOI: https://doi.org/10.29105/sillares1.2-5 
Roble. De tal modo, cuando el sacerdote realizó una procesión con el Santísimo, con ocasión de la inauguración del templo de San Luis Gonzaga en 1923, quienes sostuvieron el palio fueron los destacados empresarios Isaac Garza, Francisco G. Sada, José A. Muguerza y José Calderón. ${ }^{79}$ Por su parte, el padre Pablo Cervantes fue un gran promotor de la Doctrina Social de la Iglesia y colaboró con algunos círculos de obreros católicos en Monterrey. ${ }^{80}$

Ahora bien, cabe destacar algunos factores que incidieron en el inicio de los procesos de canonización de estas cinco personas en el corto lapso de 1991-1995. En primera instancia, puede señalarse que el cambio de la normativa romana para dichos casos simplificó los procesos, tal como ya se mencionó previamente, lo cual favoreció que hubiera menos obstáculos (trámites, objeciones, etc.) para iniciar las causas de canonización. Lo anterior permite explicar porqué el impulso más decisivo a estos procesos se dio desde mediados de los años 80 , considerando que la normatividad cambió en 1983. Un segundo factor es el hecho de que los cinco candidatos hayan sido clérigos, pues, según afirma Jean Meyer, "es mucho más fácil armar el expediente de un sacerdote que el de un laico", que puede ser "un campesino desconocido y analfabeto".

79 José Ortiz Bernal, Juan José Hinojosa Cantú. Siervo de Dios (Monterrey: Gobierno del Estado de Nuevo León, 1994), 14-15.

80 Camacho Pérez, "El catolicismo social en la Arquidiócesis de Monterrey, 1874-1926: entre el avance de la modernidad y el proyecto de restauración del orden social cristiano", 85.

Sillares, vol. 1, núm. 2, 2022

DOI: https://doi.org/10.29105/sillares1.2-5 
Además, en los procesos de canonización "finalmente se impuso la solidaridad gremial entre los sacerdotes". ${ }^{81}$

Así, el hecho de todos sean clérigos puede interpretarse en dos sentidos: por una parte, obedece a una relativa facilidad de los procesos, al haber mayor información disponible sobre ellos, y por otro lado, implica una tendencia clericalista, donde la élite eclesiástica sólo reconoce a "los suyos" y los presenta como modelos de vida cristiana para el conjunto de la feligresía. Un tercer aspecto a considerar son los recursos económicos necesarios para el desarrollo de los procesos. En Monterrey, la Iglesia ha contado con importantes patrocinios de las élites económicas, que han financiado obras caritativas, centros educativos, templos, etc. Así pues, dado que se requieren importantes sumas de dinero para el desarrollo de las causas de canonización, como ya se ha señalado, puede inferirse que las élites regiomontanas fungieron como patrocinadores indispensables de dichos procesos, cuando menos en su etapa inicial.

El cuarto factor que puede destacarse es la figura del arzobispo regiomontano que dio cauce a todos los procesos en curso: Adolfo Suárez Rivera. Él era originario de San Cristóbal de las Casas, Chiapas, nacido en 1927. Como sacerdote, fue impulsor de la recepción del Concilio Vaticano II. Fue luego obispo de Tepic (1971) y Tlalnepantla (1980), hasta ser trasladado a la sede regiomontana (1984). Ahí “manifestó su interés por promover la

81 Citado por: Vera, "La Iglesia discrimina a mártires laicos: Jean Meyer".

Sillares, vol. 1, núm. 2, 2022

DOI: https://doi.org/10.29105/sillares1.2-5 
doctrina social cristiana, el bienestar de la persona humana, la solidaridad para con los más necesitados y la participación activa de la sociedad en la vida política". Asimismo, ocupó la presidencia de la Conferencia del Episcopado Mexicano entre 1988 y 1994, donde desempeñó una esencial labor diplomática. ${ }^{82}$ De lo anterior se desprende que su trabajo pastoral se enfocó particularmente en la acción social y la gestión política.

Durante su período al frente de la Iglesia de Monterrey, el catolicismo consolidó su presencia social (si bien el porcentaje de católicos disminuyó ante el avance de otras religiones): las vocaciones sacerdotales crecieron significativamente y se construyó un nuevo seminario, se verificó la segunda visita papal en 1990, se llevó a cabo una reorganización pastoral en decanatos y zonas, se crearon nuevas parroquias y se realizó el primer sínodo diocesano, entre otras acciones. Su prestigio e influencia tuvieron como corolario la investidura cardenalicia en $1994 .{ }^{83}$

No obstante, su personalidad no estuvo exenta de conflictos. Así, aspectos como su apoyo al obispo Samuel Ruiz de San Cristóbal de las Casas o su anuencia para el retorno de los jesuitas a Monterrey, sirvieron de pretexto para que fuera acusado de ser un promotor de la Teología de la Liberación ante Roma,

82 Jesús Treviño Guajardo, Don Adolfo Antonio Suárez Rivera y su liderazgo en las reformas constitucionales, en materia de libertad religiosa, a finales del siglo $X X$. Con motivo de su décimo aniversario luctuoso (Ciudad de México, 2018), 1-5, https://arquidiocesismty.org/arquimty/wp-content/ uploads/2018/03/cardenal-suarez.pdf.

83 Treviño Guajardo, 10.

Sillares, vol. 1, núm. 2, 2022

DOI: https://doi.org/10.29105/sillares1.2-5 
los obispos y las élites regiomontanas, por parte de influyentes figuras, como el padre Marcial Maciel. Ello lo llevó a padecer problemas de salud y a presentar su renuncia al arzobispado antes de cumplir la edad canónica; sin embargo, el nuncio Justo Mullor y El Vaticano lo ratificaron. ${ }^{84}$ Dejó su cargo finalmente en 2003 y falleció cinco años después.

De tal modo, se pone de relieve que el arzobispo Suárez Rivera fue un clérigo influyente y poderoso, preocupado por el catolicismo social y que llevó a la Iglesia regiomontana a una era apoteósica. Esto permite comprender el contexto en el cual se impulsaron e introdujeron las cinco causas de canonización analizadas, pues en una diócesis sin mártires y con antecedentes de una tibia religiosidad, fue esencial el liderazgo de monseñor Suárez para encausar los procesos. Además, es destacable el hecho de que el modelo de vida cristiana que dichos candidatos representan implica una alta valoración del catolicismo social, así como de la vida clerical y del desarrollo eclesiástico en Monterrey durante la primera mitad del siglo XX.

\section{Consideraciones finales}

Las condiciones del catolicismo neoleonés (zona periférica, de frontera, con una religiosidad débilmente arraigada y de carácter pragmático) incidieron para que no destacaran figuras religiosas en

84 Alberto Athié, "Norberto Rivera o el tótem de la impunidad", en Norberto Rivera. El Pastor del poder (Ciudad de México: Penguin Random House, 2017), 97-98.

Sillares, vol. 1, núm. 2, 2022

235

DOI: https://doi.org/10.29105/sillares1.2-5 
la localidad hasta fines del siglo XIX. Fue entonces cuando el auge industrial y el compromiso religioso de las élites socioeconómicas locales, favorecieron una religiosidad más devota, conservadora, organizada, misionera y con el apoyo de grupos de poder. Debido a lo anterior, y por las propias condiciones locales, se promovieron prioritariamente los postulados del catolicismo social desde las últimas décadas del siglo XIX y las primeras del XX, creándose múltiples asociaciones de religiosos y laicos activos.

Paralelamente, estos procesos iniciaron un espíritu combativo frente al secularismo oficial y a los ambientes persecutorios, en especial desde la Revolución hasta 1940, aunque dicha resistencia puede calificarse de subrepticia y pasiva. De tal modo, el perfil de los religiosos que se encuentran en vías de canonización manifiesta al menos dos cosas esenciales: el proceso de fortalecimiento y arraigo del catolicismo neoleonés, del cual ellos fueron artífices destacados, y la importancia del catolicismo social como perfil y prioridad de la Iglesia regiomontana, en el contexto industrial y moderno.

Por otro lado, para toda diócesis es primordial tener causas de canonización, pues manifiestan la vitalidad y éxitos de la Iglesia local, y permiten presentar a la feligresía modelos cercanos y concretos de vida cristiana. En el caso de México, algunas diócesis cuentan ya con diversos santos o beatos, y múltiples procesos de canonización, como las Arquidiócesis de México y Guadalajara, pero la de Monterrey no ha logrado la exitosa culminación de proceso alguno y sólo cuenta con cinco causas. Esto implica un aparente carácter marginal del Sillares, vol. 1, núm. 2, 2022 
catolicismo neoleonés, aunque también puede deberse a un factor circunstancial muy importante: la ausencia de sangrientas persecuciones religiosas en el Noreste (pese a que sí hubo algunas medidas anticlericales radicales, especialmente en 1914).

Lo anterior derivó en que no existan mártires en la época contemporánea, algo que sí ha favorecido a los procesos de Guadalajara, por ejemplo, por tratarse de una zona cristera que cuenta con numerosos mártires. Asimismo, el primer santo mexicano, san Felipe de Jesús, originario de la Ciudad de México, también alcanzó la santidad gracias a la "corona del martirio" en Japón. No obstante, cabe agregar que sí hubo mártires entre los misioneros norestenses durante la primera época de la evangelización, como el caso de fray Martín de Altamirano en 1606, pero su sacrificio no se conserva de manera particular en la memoria colectiva y su causa de canonización no ha sido promovida.

Finalmente, ¿cuál es el modelo de vida cristiana que presenta la Iglesia regiomontana a los feligreses a partir de los procesos de canonización que ha promovido? Un modelo de carismas que se manifiestan en las virtudes heroicas (no el martirio), a través de la vida religiosa (no hay laico alguno), y evangelizando el mundo empresarial y obrero a través de la doctrina y prácticas del catolicismo social. Además, se pone de relieve que el "gran salto adelante" de la Iglesia regiomontana se verificó en la primera mitad del siglo $\mathrm{XX}$, pues previamente no hubo figuras (ni laicos ni religiosos) que destacaran como candidatos a los altares, o bien, su preponderancia quedó en el Sillares, vol. 1, núm. 2, 2022 
olvido, y la debilidad y marginalidad de la Iglesia institucional de Nuevo León impidió que se diera cauce a proceso alguno.

\section{Referencias}

"Consideran estrategia política la santificación de mártires". Reforma. Consultado el 15 de junio de 2000. https://reforma.vlex.com.mx/vid/consideran-estrategia-santificacion-martires-80987604.

"Canonización calculada". Proceso, el 15 de octubre de 2006.

"Causas de Canonización. Pasos hacia la canonización". Familia de la Cruz. Consultado el 12 de julio de 2018. http://www. causascanonizacion.org/pasoshacialacanonizacion.htm.

"Polémica en México sobre la aparición de la Virgen de Guadalupe". El País, el 31 de mayo de 1996.

"Biografía y resumen cronológico". Causa Padre Juan José Hinojosa Cantú, 2018. http://www.causapadrejuanjosehinojosacantu. com.mx/biografia-del-siervo-de-dios-cngo--juan-jose-hinoj_1.html.

"Infancia y vocación". Causa de beatificación y canonización, 2018. https://www.padrejardon.org.mx/.

Sierva de Dios Sor Gloria María Elizondo García, Misionera Catequista de los Pobres. Monterrey: Congregación Misioneras Catequistas de los Pobres, s/f.

"Sanctorum Mater. Instrucción sobre el procedimiento instructorio diocesano o eparquial en las Causas de los Santos". Consultado el 11 de julio de 2018. http://www.vatican.va/ roman_curia/congregations/csaints/documents/rc con_csaints doc_20070517_sanctorum-mater_sp.html\#INTRODUCCIÓN.

"Normae servandae in inquisitionibus ab Episcopis faciendis in Causis Sanctorum. Constitución sobre las normas que han de observarse en las investigaciones que hagan los obispos en las Causas de los Santos". Consultado el 12 
de julio de 2018. http://www.causesanti.va/content/causadeisanti/ it/documenti/normae-servandae es.html.

"Lumen Gentium. Constitución Dogmática sobre la Iglesia". Consultado el 11 de julio de 2018. http://www.vatican.va/archive/ hist_councils/ii_vatican_council/documents/vat-ii_const_19641121 lumen-gentium_sp.html.

"Hagiography Circle". Consultado el 3 de octubre de 2018. http:// newsaints.faithweb.com/.

"Santos y beatos mexicanos". Consultado el 14 de julio de 2018. http://www.arquidiocesisdepuebla.mx/index.php/arquidiocesis/santos-y-beatos-mexicanos/beatos?start $=20$.

"Causas de canonización en Arquidiócesis de Monterrey". Consultado el 19 de julio de 2018. http://www.arquidiocesismty. org/causas-de-canonizacion.php.

"Acta de fundación de Monterrey. Anexo núm. 1". Consultado el 16 de julio de 2018. http://cdigital.dgb.uanl.mx/ la/1020110039/1020110039.PDF.

"Catecismo de la Iglesia Católica". Consultado el 11 de julio de 2018. http://www.vatican.va/archive/catechism_sp/p3s1c3a2 sp.html\#IV La santidad cristiana.

Athié, Alberto. "Norberto Rivera o el tótem de la impunidad". En Norberto Rivera. El Pastor del poder. Ciudad de México: Penguin Random House, 2017.

Barranco, Bernardo. "Canonización y polémica del 'niño cristero"”. Milenio, el 19 de octubre de 2016. http://www.milenio. com/opinion/bernardo-barranco/posteando/canonizacion-y-polemica-del-nino-cristero.

Barrera López, Luis. "Reviven reliquias de Santa Librada". El Mañana, el 10 de marzo de 2018. http://www.elmanana.com. mx/noticia/97178/Reviven-reliquias--de-Santa-Librada.html.

Bernabé, Mónica. "El Papa reforma los procesos de canonización para asegurar su transparencia financiera”. El Mun-

Sillares, vol. 1, núm. 2, 2022

DOI: https://doi.org/10.29105/sillares1.2-5 
do, el 10 de marzo de 2016. http://www.elmundo.es/sociedad/2016/03/10/56e1a17422601d031a8b45b7.html.

Bonfil Batalla, Guillermo. "Los niños mártires de Tlaxcala". Cuadernos Nexos, mayo de 1990. https://www.nexos.com.

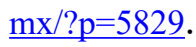

Camacho Pérez, Luis Fidel. "El catolicismo social en la Arquidiócesis de Monterrey, 1874-1926: entre el avance de la modernidad y el proyecto de restauración del orden social cristiano". Universidad Autónoma de Nuevo León, 2017.

Campos, Hermes. El mundo del Padre Raymundo. Monterrey:

Sociedad de Amigos del Padre Jardón, 2000.

Cavazos Garza, Israel. Crónicas y sucedidos del Monterrey virreinal. Monterrey: Universidad Autónoma de Nuevo León - Facultad de Filosofía y Letras, 2009.

Cavazos Garza, Israel. Breve historia de Nuevo León. México, DF: El Colegio de México; Fideicomiso Historia de las Américas; Fondo de Cultura Económica, 2003.

Cavazos Garza, Israel. “La educación en Nuevo León, en 1813. Informe del Obispo Don Primo Feliciano Marín de Porras sobre el Seminario de Monterrey". Actas. Historia, Letras y Artes. Monterrey, 1979.

Florescano, Enrique. Historia de las historias de la nación mexicana. México, DF: Taurus, 2002.

Francisco. "Maiorem hac Dilectionem. Carta Apostólica en forma de 'Motu Proprio' sobre el ofrecimiento de la vida". Consultado el 12 de julio de 2018. https://w2.vatican.va/ content/francesco/es/motu_proprio/documents/papa-francesco-motu-proprio_20170711_maiorem-hac-dilectionem.html.

García Méndez, Maribel. "Credibilidad y opinión pública entre estudiantes de Ciencias de la Comunicación y Derecho:

Sillares, vol. 1, núm. 2, 2022

240

DOI: https://doi.org/10.29105/sillares1.2-5 
Caso la Iglesia Católica”. Universidad de las Américas Puebla, 2004. http://catarina.udlap.mx/u_dl_a/tales/documentos/ lco/garcia_m_m/ capitulo3.pdf.

Guerrero, Vicente. "Santos entre los regios". El Norte, el 4 de febrero de 2001. https://norte-monterrey.vlex.com.mx/vid/santos-regios-78203979.

Henneberger, Melinda. "Ideas \& trends; the Saints just keep marching in". New York Times, el 16 de julio de 2018. https:// www.nytimes.com/2002/03/03/weekinreview/ideas-trends-thesaints-just-keep-marching-in.html.

Juan Pablo II. "Divinus Perfectionis Magister. Constitución Apostólica sobre la nueva legislación relativa a las Causas de los Santos". Consultado el 11 de julio de 2018. http://w2. vatican.va/content/john-paul-ii/es/apost_constitutions/documents/ hf jp-ii apc 25011983 divinus-perfectionis-magister.html.

Mendoza Delgado, Enrique. "Miguel Agustín Pro, mártir de la fe". Revista Verbo, 1988. http://www.fundacionspeiro.org/verbo/1988/V-269-270-P-1169-1194.pdf.

Ortiz Bernal, José. Juan José Hinojosa Cantú. Siervo de Dios. Monterrey: Gobierno del Estado de Nuevo León, 1994.

Roel, Santiago. Nuevo León. Apuntes históricos. Monterrey: Castillo, 1980.

Rubial García, Antonio. La santidad controvertida: Hagiografia y conciencia criolla alrededor de los venerables no canonizados de Nueva España. México, DF: Universidad Nacional Autónoma de México; Fondo de Cultura Económica, 2015.

Rubial García, Antonio. "Los santos milagreros y malogrados de la Nueva España”. En Manifestaciones religiosas en el mundo colonial americano, editado por Clara García Ayluardo y Manuel Ramos Medina. México, DF: Instituto Nacional de Antropología e Historia; Condumex - Centro de Estudios de Historia de México; Universidad Iberoamericana, 1997.

Sillares, vol. 1, núm. 2, 2022

DOI: https://doi.org/10.29105/sillares1.2-5 
Saldaña Martínez, Moisés A. El anticlericalismo oficial en Nuevo León, 1924-1936. Monterrey: Universidad Autónoma de Nuevo León - Facultad de Filosofía y Letras, 2009.

Sánchez Morales, Aurelia Guadalupe, Virginia Saro Serrato, y Ángel Tello Hernández. Arquidiócesis de Monterrey, N. L., México. Investigación estadística y documental. Monterrey: Secretariado Social Arquidiocesano, 1981.

Smith, Williams, y Samuel Cheetham. A Dictionary of Christian Antiquities. https://archive.org/stream/dictionaryofchri01smituoft/ dictionaryofchri01smituoft djvu.txt, 1875.

Tapia Méndez, Aureliano. Pablo Cervantes, un sacerdote de su tiempo. México, DF: Jus, 1971.

Tapia Méndez, Aureliano. El diario de Ipandro Acaico. Monterrey: Al Voleo-El Troquel, 1988.

Tovas Esquivel, Enrique, y Adriana Patricia Garza Luna. "La capilla de San Caralampio. Una presencia fugaz en Monterrey”. Boletín de monumentos históricos, núm. 6 (2006): 19-26. https://revistas.inah.gob.mx/index.php/boletinmonumentos/ article/view/1996/1926.

Treviño Guajardo, Jesús. Don Adolfo Antonio Suárez Rivera y su liderazgo en las reformas constitucionales, en materia de libertad religiosa, a finales del siglo XX. Con motivo de su décimo aniversario luctuoso. Ciudad de México, 2018. https://arquidiocesismty.org/arquimty/wp-content/uploads/2018/03/ cardenal-suarez.pdf.

Uribe, Mónica. "La ultraderecha en México: el conservadurismo moderno". El Cotidiano 23, núm. 149 (2008): 39-57. http://www.redalyc.org/pdf/325/32514905.pdf.

Vázquez, Abraham. "El historiador y cronista Carlos González y los arqueólogos Aracely Rivera y Enrique Tovar trazan 
aquí esta cartografía de lugares de ayer". El Norte, el 12 de mayo de 2008.

Velarde, Gustavo. Los Arzobispos Martín y Guillermo Tritschler y Córdova. Semblanza biográfica y genealógica. Puebla: Mercadeo Múltiple División Editorial, 2008. https://issuu. com/gustavovelarde-tritschler/docs/los arzobispos_mart n_y_guillermo $336496 \mathrm{fca} 742 \mathrm{~d} 3$.

Vera, Rodrigo. "La Iglesia discrimina a mártires laicos: Jean Meyer". Proceso, el 15 de abril de 2000. https://www.proceso. com.mx/183033/la-iglesia-discrimina-a-martires-laicos-jean-meyer.

Zaldívar, Sergio. "Los beatos de Oaxaca". Proceso, el 27 de julio de 2002. https://www.proceso.com.mx/187969/los-beatos-de-oaxaca.

\section{Entrevistas}

Martínez de Salazar, Margarita. Entrevista realizada por Moisés Saldaña el 25 de julio de 2018.

Rodríguez Cárdenas, Javier. Entrevista realizada por Moisés Saldaña, el 20 de septiembre de 2018. 